\title{
Café com leite: \\ simulacros da criança em jingles infantis
}

Lucas Takeo SHIMODA

(Universidade de São Paulo)

RESUMO: A publicidade infantil trabalha com diversos simulacros da criança a fim de persuadir mais eficazmente o enunciatário. Analisamos os jingles criados para o Café Seleto e para o Leite Parmalat. Neste trabalho, privilegiamos a relação da criança com o produto anunciado, propondo uma tipologia dos alimentos.

PALAVRAS-CHAVE: semiótica; publicidade; simulacro; jingle

ABSTRACT: Children's advertising deals with different child simulacra in order to persuade the enunciatee more efficiently. This article analyzes two jingles written for Café Seleto and Leite Parmalat, focusing on the relationship between the child and the product and proposing a typology of the advertised goods.

KEYWORDS: semiotics; advertising; simulacrum; jingle 


\section{INTRODUÇão}

Apesar do seu crescimento notável, os estudos sobre a publicidade em geral têm se detido principalmente no aspecto visual em análises de anúncios impressos ou televisivos, relegando a sonoridade a um segundo plano. Tendo em vista essa lacuna, este trabalho pretende lançar um olhar semiótico sobre os jingles, que podem ser definidos de maneira sucinta como "uma canção breve voltada para a divulgação de produtos". Espera-se que a análise dos jingles infantis possa revelar alguns mecanismos de construção da imagem da criança. Para tal, investigaremos a dinâmica narrativa envolvendo os papéis temáticos da criança e do adulto, a serem mais bem detalhados ao longo da análise comparativa de dois jingles elegidos por exporem de maneira peculiar as relações postas entre esses sujeitos e o produto anunciado.

Considerando esta dinâmica entre sujeitos e objeto, foi elaborada uma tipologia dos alimentos com base no modelo do quadrado semiótico das modalidades veridictórias, bem como nos valores de consumo conforme estabelecidos por JeanMarie Floch (1995). A depender dos valores investidos no objeto, é possível caracterizar mais acuradamente os sujeitos tendo em vista a junção, pois "o sentido referente à pessoa provém do sentido concernente às coisas, pois o gosto é um sistema de classificação aplicado aos objetos que define os sujeitos que entram em conjunção com eles" (Fiorin, 1997:18). Aliando a configuração modal dos sujeitos aos valores concretizados no objeto, pretende-se verificar como a criança é retratada nos universos discursivos relacionados ao consumo.

\section{TOMAR CAFÉ}

Veiculado em 1978, o jingle criado para o Café Seleto ${ }^{1}$ apresenta de maneira quase didática um esquema actancial arquetípico que compreende adultos e crianças. Percebese claramente a presença de três timbres ao longo do jingle que podem ser tomados como guias para condução de análise. As duas primeiras partes são entoadas por um timbre identificado como infantil. Com ligeiras variações da linha melódica em relação aos segmentos anteriores, a terceira parte é entoada por um coro de vozes mistas adultas (o qual inclui a voz "infantil" em seu registro natural), enquanto o terceiro timbre aparece na voz masculina do locutor sobre a canção, como freqüentemente ocorre nos jingles.

A partir desta breve verificação de timbres, é possível inferir a presença de três atores diferentes na cena enunciativa. Desse modo, tanto o simulacro de criança quanto o coro misto se atém ao plano do enunciado enquanto o locutor, caracterizado pela prosódia da fala cotidiana, flagra a enunciação. Esta delegação de vozes operada pelo enunciador mostra como o timbre participa das estratégias de persuasão deste texto cancional de tal modo que tomaremos essa categoria como guia para conduzir nossa análise. Em vista disso, por uma questão meramente prática, denominaremos doravante "parte I" o conjunto de frases melódicas entoadas pelo timbre infantil (a saber, os segmentos 1 e 2); empregaremos "parte II" para o trecho entoado pelos timbres adultos, ou seja o segmento 3 e a frase do locutor.

Voltando o olhar para a parte I, encontramos duas marcas mais relevantes da categoria de pessoa: "a gente" e "mamãe". A debreagem actancial enunciativa operada 
por "a gente" associa o narrador ao enunciador manifestado pelo timbre infantil. Esta expressão desencadeia pelo menos duas possibilidades de leitura, pois pode indicar tanto um "nós" coletivizado quanto um "eu e você", induzindo o enunciatário a adotar os valores ali apresentados. É necessário lembrar ainda que, em português brasileiro, a expressão "a gente" é típica do registro familiar, o que desempenhará um papel importante na semântica discursiva deste texto, como veremos posteriormente. De qualquer modo, este efeito enunciativo é reafirmado pelas conjugações verbais presentes nestes dois primeiros segmentos.

Por sua vez, a debreagem actancial enunciva operada por "mamãe" tem papel fundamental na construção de sentidos desse jingle. Entoada pelo timbre infantil, essa expressão remete nitidamente ao ator "coro de adultos", que aparecerá logo em seguida no segmento 3. Aqui, o sujeito operador "mamãe" é apresentado como dotado de um /poder/ e um /saber/ preparar bem o café (ou ainda, construí-lo como objeto de valor, para retomarmos Greimas ${ }^{2}$ ), além de um /querer/ assinalado pela expressão "com todo o carinho".

Entoado pelo coral de adultos, o terceiro segmento só vem confirmar esta leitura. O revestimento timbrístico deste trecho apresenta no plano da expressão uma pluralidade de atores para o actante "mamãe" do plano do conteúdo que aqui toma a voz enunciante, já que o componente lingüístico-melódico traz à tona as modalidades do /saber/ e do /crer/ desse sujeito que, cumprindo seu papel de destinador-julgador, interpreta como verdadeiras (/parecer/ + /ser/) as qualidades do objeto-valor Café Seleto ("sabor delicioso", "cafezinho gostoso").

A respeito deste, é interessante notar como um mesmo objeto pode congregar valores distintos a depender das relações contraídas com os sujeitos. O valor atribuído ao objeto-valor Café Seleto pelo sujeito "criança" não reside nas suas propriedades internas, mas sim no seu papel dentro do contrato fiduciário estabelecido entre destinador-mamãe e destinatário-criança. A relação de confiança entre estes sujeitos é assinalada pela intensidade tímica investida no café, manifestada no componente lingüístico pela expressão "com todo carinho" e no plano da expressão pelos amplos saltos intervalares (ver Tabela 1 e 2). Dessa maneira, a carga passional se volta mais para as interações subjetais do que para a conjunção com o objeto em si mesmo, de modo que o café se apresenta como um sinal de reafirmação do contrato fiduciário.

Em contrapartida, o objeto "café Seleto" é caracterizado na parte II pelos seus atributos intrínsecos. No segmento 3, podemos verificar também alguns traços de passionalização, como os saltos intervalares (ver Tabela 3) e a ampliação da tessitura melódica da voz infantil, especialmente na frase "É o café Seleto", em que a sílaba "fé" se projeta para o ponto mais agudo da canção. Nessa região, a repetição da expressão "café Seleto" em tonema descendente aponta para o estado passional de conjunção eufórica do sujeito com o objeto-café. Ao contrário do que ocorre na parte I, os recursos passionalizantes visam a exaltação do objeto e suas qualidades, relacionadas sobretudo aos traços gustativos (“delicioso", "gostoso").

Tendo isso em vista, podemos notar algumas diferenças entre este trecho e a frase do locutor. Em ambos, o objeto-café é valorizado pelas suas características intrínsecas, porém os modos de abordá-lo apontam para diferentes estratégias de persuasão. Na frase "Café Seleto é torrado eletronicamente", é o /saber/ do sujeito sobre 
o objeto-café que sobressai, marcado pela expressão "eletronicamente" e, sobretudo, pela prosódia da fala cotidiana em tom asseverativo. A palavra falada na voz masculina do locutor privilegia a modalidade epistêmica, pois, conforme afirma Luiz Tatit, "a oposição entre canção e linguagem oral contrapõe, em suma, a dimensão estética da primeira à dimensão intelectiva ou utilitária da segunda" (Tatit, 1997:149). Já no segmento 3, as características do café apresentadas no componente lingüístico são moduladas pelos traços passionalizantes da curva melódica. Ao convocar a ordem do sensível, a palavra cantada visa mobilizar os estados tímicos do enunciatário enquanto a frase do locutor enfoca a ordem do inteligível.

Deve-se ressaltar ainda o papel do timbre nessa distinção. No segmento 3, o ator "coro de adultos" é figurativizado no plano da expressão por um "coral", ao passo que a frase seguinte é pronunciada por uma única voz. A isso se contrapõe a voz singular do locutor que, por meio da palavra falada, apaga o sensível para enfocar as propriedades inteligíveis do produto. $\mathrm{O}$ /saber/ encontra-se então concentrado num ator individual ("locutor") enquanto o /crer/ está difundido na pluralidade dos "adultos". Estes dois esquemas valorativos se cruzam num mesmo objeto, construindo-o em sua totalidade: o café merecerá a apreciação estética gustativa do enunciatário porque este sabe (ou ainda, passa a saber) sobre o processo de sua elaboração ("torrado eletronicamente").

Até aqui podemos notar então que o objeto-valor "café Seleto" encontra-se no centro da arquitetura desse texto, contraindo relações de diversa natureza com os sujeitos. Para o actante /adulto/ (o qual subsume os atores "coro de adultos" e "locutor"), o café se valoriza na relação objetal; já para o actante /criança/, o valor deste objeto se orienta pela relação subjetal entre destinador-adulto e destinatário-criança, conforme traçamos anteriormente. Num segundo nível, o ator "coro de adultos" se distingue do ator "locutor" pela modulação dos valores atribuídos ao objeto a serem partilhados pelo enunciatário. Para o primeiro, prevalece o caráter sensível; para o segundo, é a ordem do inteligível que vem à tona.

\section{BEBER LEITE}

Criado em 1998 pela agência DM9DDB para a campanha "Porque nós somos mamíferos" da Parmalat, este jingle ${ }^{3}$ é entoado por um único timbre adulto. De um modo geral, predomina o processo de figurativização, com alguns traços esparsos de passionalização. No componente lingüístico, pode-se segmentar o texto em duas partes bem distintas, tomando a categoria de pessoa como parâmetro. Na primeira (doravante "parte A"), são apresentados paradigmaticamente diversos animais que partilham entre si o gosto pelo leite Parmalat; predomina portanto a debreagem actorial enunciva. Já na Coda da Parte B (doravante apenas "Coda"), a enumeração dá lugar à interpelação operada pelos verbos no imperativo, instalando uma debreagem actorial enunciativa que revela a presença do enunciador adulto no enunciado.

Instaurando logo de início uma isotopia figurativa da /zoomorfia/, os nomes de animais apresentados em sequiência ao longo da parte A podem ser todos subsumidos pelos termos "filhote" e "bichinho" presentes na Coda. O uso das formas do diminutivo em "vaquinha", "foquinha", "ursinho" e "bichinho" marca a afetividade, além de ser típica do tratamento familiar em português brasileiro. Deste modo, temos uma série de 
atores (onze ao total) que recobrem o mesmo actante "filhote". A escolha deste termo, retirado do próprio texto, não se dá por acaso. Segundo o dicionário Aurélio, "filhote" pode designar tanto "cria de animais" quanto "diminutivo de "filho"”. O emprego dos diminutivos acima mencionados reafirma assim a isotopia da /antropomorfia/ presente no vocábulo "filhote". Além de corroborar a leitura bi-isotópica do texto, o efeito enunciativo causado pelo imperativo "mantenha" e pelo dêitico "seu" trazem ao plano da enunciação o actante "filhote" que na parte A se mantinha no plano do enunciado. $\mathrm{O}$ enunciatário é transformado de maneira peculiar em um sujeito ao mesmo tempo /antropomórfico/ e /zoomórfico/, que deve manter o seu "filhote forte".

No nível narrativo, temos aqui novamente uma relação subjetal que, ao contrário do que ocorre no jingle do Café Seleto, compreende dois actantes adultos (a saber, S1-enunciador e S2-enunciatário). Entre eles se estabelece um contrato segundo o qual o sujeito "filhote" deve ser mantido em conjunção com os valores eufóricos da vitalidade ("forte"). As paixões eufóricas aí investidas se manifestam não só pelo andamento acelerado da canção, mas também pela elevação da curva melódica, que atinge pela primeira vez a nota mais aguda na última sílaba do imperativo "vamos lá!". Este clímax melódico aliado ao efeito enunciativo confere a este trecho o tom de convocação, visando cooptar as disposições tímicas de S2. Logo em seguida, a tensão passional se desfaz para que S1 transmita, em tonema descendente, o /saber/ manter a criança forte. Para tal, basta a S2 dispor de "amor" e "Parmalat", que figurativizam respectivamente o /querer/ e o /poder/.

Ora, a primeira modalidade já é doada por S1 no próprio ato enunciativo, como pode ser verificado pelos traços de passionalização da curva melódica. Resta então ao já manipulado S2 adquirir o /poder/ do leite Parmalat para que ele possa enfim doar ao sujeito "filhote" o objeto-valor "saúde". Os resquícios de disforia aparecem virtualizados no aspecto durativo do verbo "mantenha". Cabe a S2 assegurar a continuidade dessa conjunção, pois, de outro modo, o sujeito "filhote" não se tornaria suficientemente competente (/não-poder/) para garantir a posse de seu objeto-valor, não obstante seu /querer/ aflorado por todo o texto ("o panda e a vaquinha só querem Parmalat", "o rinoceronte só quer leite Parmalat"). A ameaça de um anti-sujeito virtualizado permanece distante graças à atuação intensa de S2, que cumpre neste programa narrativo o papel de destinador.

Desse modo temos então, homologados a suas respectivas categorias do plano da expressão, três programas narrativos principais, dos quais os dois primeiros se colocam no plano do enunciado e o último no plano da enunciação. Este se caracteriza pela factitividade inscrita nos imperativos ao passo que aqueles se compõem de enunciados do /ser/. É interessante notar que os verbos "mia" e "late" não indicam o /fazer/, afinal não sinalizam qualquer transformação de estados (Greimas \& Courtés, 1989:178-179). Ao contrário, os valores profundos da continuidade já manifestados nos trechos precedentes da canção são evidenciados pela própria construção gramatical deste trecho com os verbos intransitivos no chamado "presente gnômico". Essa operação discursiva estabelece assim um efeito de verdade universal da qual a marca Parmalat participa de maneira meticulosa ao ser incluída no paradigma formado por "mia" e "late". Assim, "querer leite Parmalat" seria algo tão espontâneo e natural (com toda a conotação lévi-straussiana do termo) quanto "miar" e "latir". Entre a /zoomorfia/ subjacente nestes verbos onomatopaicos e a /antropomorfia/ sugerida por "Parmalat" 
(pertencente à "cultura", em oposição à "natureza" dos bichinhos) temos a mediação do conector de isotopias "leite". Subsumindo estes termos polares, o vocábulo "leite" nos permite considerar uma categoria hierarquicamente superior que trataremos aqui por /mamífero/. A correlação entre os termos no nível discursivo, bem como sua homologia com as categorias fundamentais de Lévi-Strauss, estão ilustradas no quadro abaixo:

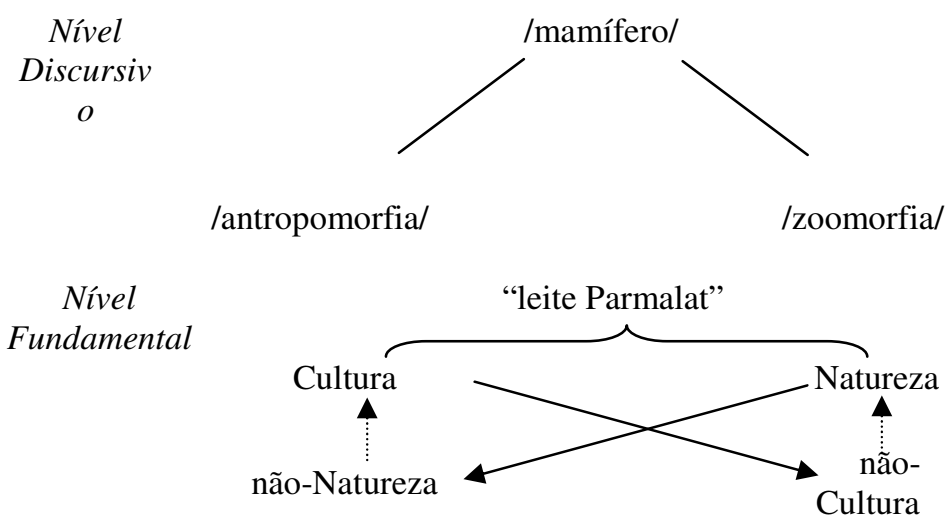

Pode-se verificar desta maneira que a biisotopia presente no jingle, marcada especialmente pelos vocábulos "leite" e "filhote", pode ser apreendida pelo termo complexo /mamífero/ que nada mais é do que uma formulação no nível discursivo equivalente ao que ocorre com o actante sincrético "filhote" do nível narrativo.

\section{VoCÊ É O QUE VOCÊ COME}

Tendo em vista a análise destes jingles, passemos a observar com mais vagar o objetoproduto anunciado por eles. A afirmação corrente no senso comum de que a publicidade visa vender "produtos" deve ser reavaliada com maior refinamento pelo ponto de vista semiótico. Apesar da aparente simplicidade, o questionamento sobre quais objetos são promovidos pela propaganda assume papel central no delineamento dos simulacros do enunciatário. Se considerarmos em termos gerais a atividade publicitária como uma macro-narrativa arquetípica, então o produto se constituirá como um objeto desejável portador dos valores partilhados entre um destinador e um destinatário. Desse modo, devemos afastar a idéia corriqueira de que o produto em si mesmo carrega de antemão as qualidades que fazem dele uma mercadoria atraente; ao contrário, é o discurso publicitário que o constrói como objeto, impregnando-o com valores axiológicos de consumo postos em jogo em cada enunciado (Floch, 1995:149-152). Assim, ao voltar os olhos para os objetos, estamos invariavelmente buscando pelos sujeitos que a ele se relacionam, já que esses dois actantes sintáticos se definem reciprocamente (Barros, 2001:29).

No jingle do Café Seleto, pudemos conferir que o objeto-café é valorizado distintamente pelos actantes "adulto" e "criança": o primeiro privilegia os atributos estéticos (especialmente os gustativos) enquanto o segundo toma-o como um mero sinal 
da fidúcia entre criança e adulto. A mediação entre sujeito-criança e objeto-café se dá apenas de maneira indireta, visto que o "tomar café" aponta antes para uma debreagem temporal enunciva do que para o ato próprio de ingerir a bebida. O consumo do café pela criança implicitado pelo biisotópico "tomar café" permanece apenas virtualizado, visto que não há qualquer menção direta às propriedades do café em si. Já para o sujeito "adulto", é a experiência da degustação do "cafezinho gostoso" que salta para o primeiro plano de tal forma que a estesia se firma para este actante como o valor principal deste objeto.

Em contrapartida, no jingle do Leite Parmalat, ambos os actantes valorizam o objeto-leite pelas suas características intrínsecas. Ao longo da parte A, o actante "filhote" é caracterizado pelo seu desejo do objeto-leite em si mesmo (como se pode verificar pela reiteração exaustiva do /querer/ no texto) ao passo que no jingle anterior o objeto-café é apenas um objeto modal com o qual se pode assegurar o contrato fiduciário. Aqui, o prazer estésico está apenas latente no gosto dos filhotes pelo objetoleite; com efeito, são as propriedades nutricionais que prevalecem ("mantenha seu filhote forte"). Pode-se notar dessa maneira como a configuração discursiva da "alimentação" pode portar variações figurativas sutis que, em última análise, transformam o conjunto dos valores postos em jogo.

Em ambos jingles, foi possível verificar uma invariante figurativa /familiar/, que encerra no nível narrativo o contrato posto entre dois sujeitos actorializados como "criança" e "adulto". Conectada a esta narratividade, há também uma invariante temática da /alimentação/ que recobre igualmente sujeitos e objeto. A um destinadoradulto cabe o /dever/ de doar a um destinatário-criança o objeto-alimento, figurativizado ora por "café", ora por "leite". Entretanto, é na relação entre os sujeitos e o objeto que repousam as variações figurativas e narrativas que acabam por determinar as ideologias inscritas em cada texto (Fiorin, 2005:106).

No jingle do Café Seleto, vimos que o objeto-café possui um valor estésico para o adulto e um valor afetivo para a criança. A fruição gustativa do café restringe-se ao actante "adulto" enquanto permanece apenas virtualizada para o actante "criança" na expressão "na hora de tomar café". Já no jingle do Leite Parmalat, o objeto-leite se define inteiramente na relação com o actante "criança", restando ao actante "adulto" a função de doar-lhe o objeto-leite. As qualidades sensoriais do leite permanecem apenas insinuadas pelo /querer/ dos filhotes em detrimento dos seus valores nutricionais capazes de manter o "filhote forte".

A partir dessas considerações, pode-se perceber que os objetos apresentam valores de natureza distinta, não obstante pertencerem à mesma isotopia da /alimentação/. Com base nestes valores, será possível delinear o simulacro de criança posto em cada texto. Na esteira dos trabalhos pioneiros reunidos por Jacques Fontanille e Alessandro Zinna em Les objets au quotidien (Fontanille \& Zinna, 2005), gostaríamos aqui de propor uma tipologia dos "objetos alimentícios" (a ser testada oportunamente na análise de outros discursos) baseada no quadrado semiótico das modalidades veridictórias. 


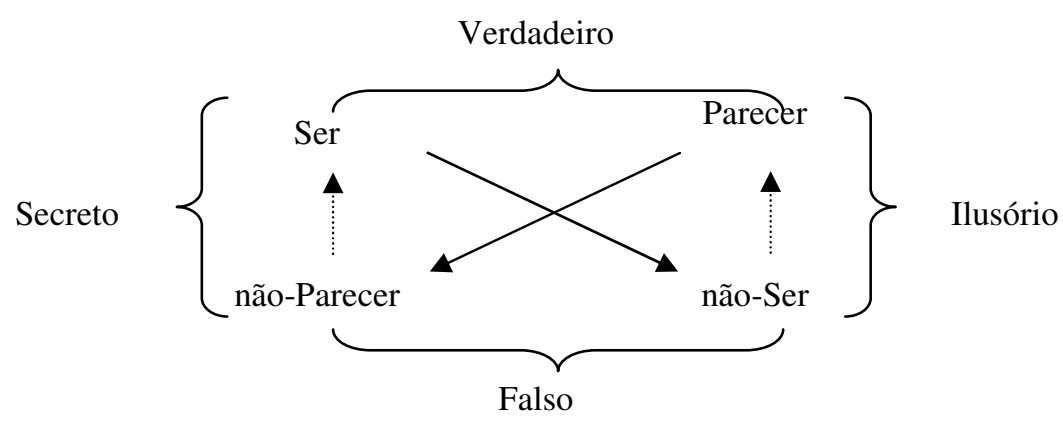

O quadrado estabelecido por Greimas e Courtés articula as modalidades do ser e do parecer, gerando uma rede hierarquicamente superior cujos metatermos podem ser nomeados como verdade, falsidade, mentira ou segredo (Greimas \& Courtés, 1979:367). Podemos transpor este modelo para o universo dos valores alimentares encontrados em nossa análise, enfocando a relação entre o sujeito "criança" e o objeto "alimento". Assim, é possível estabelecer uma oposição entre os valores utópicos da "estesia" e aqueles práticos referentes à "nutrição", que correspondem respectivamente à aparência e à imanência da relação entre sujeito e alimento.

Segundo este esquema, a Estesia refere-se ao campo do /parecer/ do objetoalimento; por pertencer ao universo da aparência, podemos relacioná-lo às sensações gustativas experimentadas pelo sujeito. É aqui que se encontram os julgamentos sobre o (bom) gosto, já discutidos com precisão por José Luiz Fiorin em De gustibus non est disputandum. Conforme já mostrou este autor, a questão do gosto se encontra primordialmente em uma norma estabelecida pelos grupos sociais ditando quais gostos são considerados bons (transformados, enfim, apenas em "gosto"), ruins ou então meramente insípidos no infinito universo da sensorialidade. (Fiorin, 1997:14-17).

Paralelamente, relacionamos ao eixo da imanência os valores da Nutrição, compreendendo aqueles efeitos do alimento sobre a vitalidade do sujeito que não são imediatamente perceptíveis, mas residem no /ser/ do alimento. Ao contrário da anterior, esta espécie de valoração pertence à esfera do inteligível na medida em que se relaciona mais às modalidades epistêmicas do que às volitivas. Enquanto a estesia própria do gosto abrange uma dimensão afetiva/passional por excelência (Barros, 1997:166), o "nutritivo" dificilmente se deixa apreender senão por um /crer/ sobre as propriedades intrínsecas daquele objeto, como é o caso das pílulas e dos complementos vitamínicos.

Conjugando os valores apresentados acima de maneira análoga ao efetuado no quadrado das modalidades veridictórias, obtemos então as quatro classes do objeto alimentício conforme as combinações de sua tonicidade gustativa e nutricional. Assim, o objeto que afirma a Nutrição e a Estesia se coloca como uma refeição essencial, simultaneamente saborosa e saudável. Também é o caso dos chamados "médicaliments", produtos inovadores que, segundo a imagem propagandeada, congregam em si os benefícios do universo medicinal sem dispensar o prazer gustativo. Do lado contrário, o objeto que nega a Nutrição e a Estesia se mostra como um alimento falso. Mesmo o seu estatuto de "alimento" pode ser questionado visto que o termo neutro implica a própria 
ausência da categoria neste contexto sêmico (Greimas, 1976:35). Cabe lembrar, no entanto, que mesmo os parâmetros do que é nutritivo variam para cada formação social ou cultural. A exemplo disto, podemos citar a proibição à carne de porco por algumas religiões ou o repúdio deliberado aos derivados do leite promovido por alguns setores do movimento naturalista (ressaltemos aqui novamente a participação fundamental do /crer/ nos julgamentos críticos dessa natureza).

Passando agora aos termos sub-contrários, o alimento que afirma a Estesia e nega a Nutrição pode ser considerado como o Supérfluo. São os alimentos valorizados pelas delícias proporcionadas por sua apreciação e não propriamente pela contingência nutricional de seus benefícios à saúde. A escolha do termo "supérfluo" pode ser justificada se retomarmos a arguta afirmação de Fiorin: "O gosto só existe quando o homem está subtraído da necessidade" (Fiorin, 1997:22). Como exemplo, podem ser mencionados os salgadinhos, as guloseimas, os aperitivos "beliscados" e tantos outros representantes do "junk food", classificação bem oportuna aos nossos propósitos. Também se incluem aqui os temperos (qual seria afinal a finalidade de um tempero senão atribuir nuances de paladar a um outro alimento?), as sobremesas e as bebidas passíveis de apreciação, como a cerveja e o vinho. Por fim, temos os alimentos que negam a Estesia e afirmam a Nutrição. A insipidez do alimento (ou ainda, a atonia de seu gosto) é compensado pela necessidade de ingestão dos nutrientes que nele estão presentes. Assim, o consumo se dá menos pelo /querer/ do que pelo /dever/. Nesta classe que denominaremos Fundamental encontram-se os mantimentos básicos que, por participarem dos rituais rotineiros da alimentação, acabam por se dessemantizar e perdem sua capacidade de excitar o paladar do sujeito. Podem ser incluídos também os remédios, as pílulas vitamínicas, em suma, todos aqueles víveres que não aprazem mas devem ser comidos simplesmente porque - conforme se diz na linguagem coloquial "faz bem". Dessa maneira, os quatro termos podem ser dispostos no quadrado semiótico como aparece no diagrama abaixo:

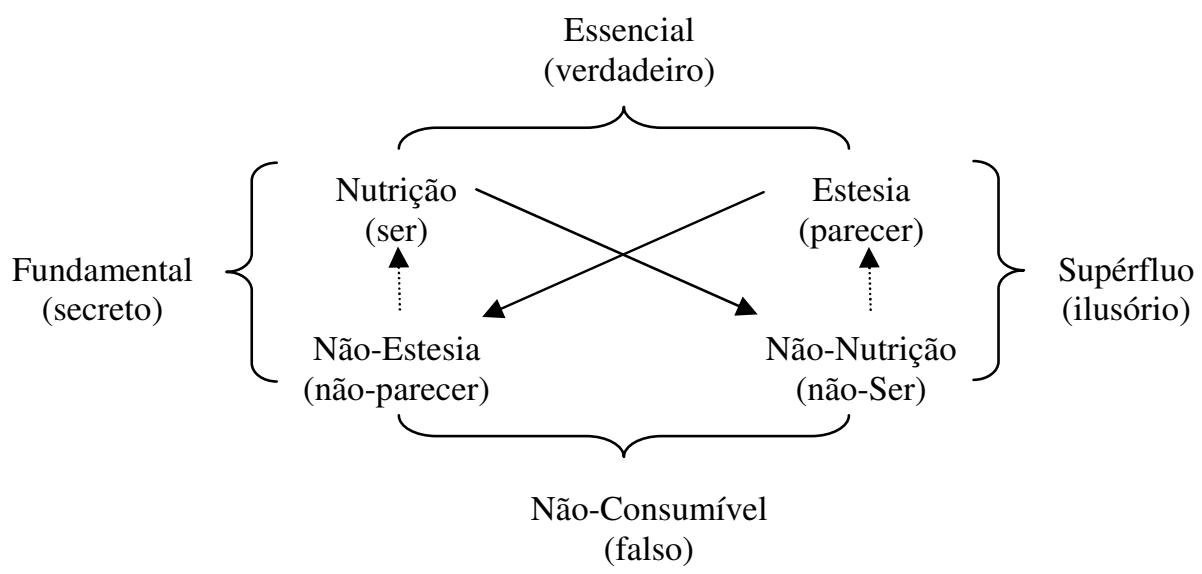

Antes de aplicarmos este esquema aos jingles cotejados, cumpre lembrar que só é possível julgar os valores do objeto-alimento considerando a sua relação juntiva com um sujeito que o consome. A economia teórica dessa tipologia poderia 
eventualmente ser questionada, por se tratar de um campo semântico específico. No entanto, estas objeções poderiam ser refutadas se considerarmos que no esquema obtido ressoa - embora por outras vias - o quadrado semiótico dos valores de consumo de Jean-Marie Floch. Assim, os termos essencial, não-consumível, supérfluo e fundamental correspondem respectivamente aos regimes de valores prático, utópico, lúdico e crítico. (cf. Diagrama 1, em Anexo). Tendo isso em vista, passemos agora a verificar como os produtos que analisamos anteriormente inflectem na imagem da criança construída nos textos em questão. Retomando as análises já traçadas, foi possível notar que a conjunção sujeito-objeto se dá de modos distintos em um e outro jingle.

No jingle do Café Seleto, podemos afirmar que tanto o sujeito adulto quanto o sujeito criança estão em conjunção com o objeto café, embora aquela seja caracterizada distintamente no texto por um e outro actante. Para o sujeito adulto, o objeto café se apresenta como Supérfluo: o "cafezinho gostoso" é saboreado sem que haja qualquer menção a suas propriedades nutritivas. Entretanto, este objeto se revela como falso para o sujeito criança. De fato, sua conjunção com o objeto-café é apenas tímico-cognitiva, haja vista seu valor de base na relação subjetal criança-adulto. Assim, afastadas as possibilidades da fruição do objeto-café, só resta ao sujeito-criança tomá-lo como Não-Consumível. É necessário ressaltar que o objeto-café ainda mantém seu valor desejável, porém despido de seu estatuto de "alimento". Em outras palavras, tudo se passa como se o café admitisse a dimensão utópica de um totem, estimado enquanto portador de valores existenciais (Floch, 1995:149).

Uma configuração bem diferente pode ser encontrada no jingle do Leite Parmalat. Neste caso, a conjunção eufórica do sujeito-filhote com o objeto-leite já descrita acima se coloca no pólo do Essencial. À satisfação gustativa subjacente no /querer/ dos bichinhos se alia o poder de nutrir e manter "forte" próprio do leite. Esta leitura pode ser corroborada por uma análise sêmica do termo "leite", cujo campo lexical conta também com "aleitar", "amamentar" e "mamífero". Este último termo, empregado por nós para definir um actante hiperonímico, subsume em si todo este campo figurativo visto que, segundo o dicionário Aurélio, é próprio das fêmeas dos mamíferos ter "glândulas mamárias que segregam leite para alimentar os filhos". Correspondente a essa função, o verbo "amamentar" denota nada mais do que "alimentar com leite". Dessa forma, podemos inferir também que "leite" retoma "mamãe" por metonímia, o que corrobora as interações actanciais já apresentadas acima. Todo este jogo de isotopias aparece condensado nos vocábulos "filhote" e "leite" presentes no jingle, já que eles abarcam tanto a /zoomorfia/ quanto a /antropomorfia/, como vimos anteriormente.

\section{5. ÚLTIMO GOLE}

Através deste breve percurso, pretendemos esclarecer algumas estratégias de persuasão empregadas na propaganda, especialmente nos jingles. Buscamos investigar a construção da imagem da criança considerando para isso tanto sua participação no esquema actancial quanto sua relação com o produto anunciado. A seleção de valores práticos ou utópicos na construção do objeto de valor já faz transparecer os simulacros do sujeito, pois este não pode existir semioticamente sem se relacionar a um objeto. A tipologia proposta aqui pode esclarecer em termos estruturais como o discurso gera 
determinados efeitos de sentido que podem, em última instância, tornar um alimento não-consumível, como ocorre no jingle do Café Seleto analisado acima. Em ambos jingles, a criança é apresentada como um destinatário do produto a ser doado pelo destinador adulto. No entanto, a associação dos diferentes valores investidos em cada objeto às isotopias da /alimentação/ e da /familiaridade/ aponta para as diferenças que identificam esses discursos. Assim, através do conceito semiótico básico de junção foi possível delinear a imagem da criança na propaganda seguindo uma metodologia operacional aplicável a outros textos publicitários.

\section{Notas}

\footnotetext{
${ }^{1}$ Ouça o jingle MESSINA, Archimedes. Café Seleto - menina. Produção Sonotec. Ano: 1978. [online] Disponível na Internet via WWW.URL:

http://www.clubedojingle.com/jingles_alimentacao.htm Arquivo consultado em 16 de novembro de 2007.

${ }^{2}$ Greimas, 1983:161.

${ }^{3}$ Ouça o jingle MINEIRO-CAMPA-BRUNETTI. Parmalat mamíferos I. Produção MCR. Ano: 1996. [online] Disponível na Internet via WWW.URL:

http://www.clubedojingle.com/jingles_alimentacao.htm Arquivo consultado em 16 de novembro de 2007.
}

\section{REFERÊNCIAS BIBLIOGRÁFICAS}

BARROS, Diana Luz Pessoa de. Teoria do discurso: fundamentos semióticos. São Paulo: Humanitas, 2001.

. Gosto bom, gosto ruim. In: LANDOWSKI, Eric; FIORIN, José Luiz. O gosto da gente, o gosto das coisas. São Paulo: EDUC, 1997.

FIORIN, José Luiz. De gustibus non est disputandum? Para uma definição semiótica do gosto. In: LANDOWSKI, Eric; FIORIN, José Luiz. O gosto da gente, o gosto das coisas. São Paulo: EDUC, 1997.

. Elementos de análise do discurso. São Paulo: Contexto 2005.

FLOCH, Jean-Marie. Identités visuelles. Presses universitaires de France: Paris, 1995.

FONTANILLE, Jacques; ZINNA; Alessandro (orgs). Les objets au quotidien. Paris: Presses Universitaires de Limoges. coll. Nouveaux Actes Sémiotiques - Recueil, 2005.

GREIMAS, Algirdas Julien. Du sens II: essais sémiotiques. Paris: Ed du Seuil, 1983. Semântica estrutural. São Paulo: Cultrix, 1976.

\& COURTÉS, Joseph. Dicionário de semiótica. São Paulo: Cultrix, 1989.

TATIT, Luiz. Musicando a semiótica. São Paulo: Annablume, 1997. 


\section{ANEXo}

(parte I) $\left\{\begin{array}{l}\text { Jingle Café Seleto (1978) } \\ 1 \\ \text { Depois de um sono bom } \\ \text { A gente levanta } \\ \text { Toma aquele banho } \\ \text { Escova o dentinho } \\ 2 \\ \text { Na hora de tomar café } \\ \text { É o café Seleto } \\ \text { Que a mamãe prepara } \\ \text { Com todo carinho } \\ \text { (parte II) } \\ \text { Café Seleto tem } \\ \text { Sabor delicioso } \\ \text { Cafezinho gostoso } \\ \text { É o café Seleto, café Seleto } \\ \text { (café Seleto é torrado eletronicamente) }\end{array}\right.$

\section{Jingle Leite Parmalat (1996)}

(parte A) $\left\{\begin{array}{l}\text { O elefante é fã de Parmalat } \\ \text { O porco cor-de-rosa e o macaco também são } \\ \text { O panda e a vaquinha só querem Parmalat } \\ \text { Assim como a foquinha, o ursinho e o leão }\end{array}\right.$


Tabela 1

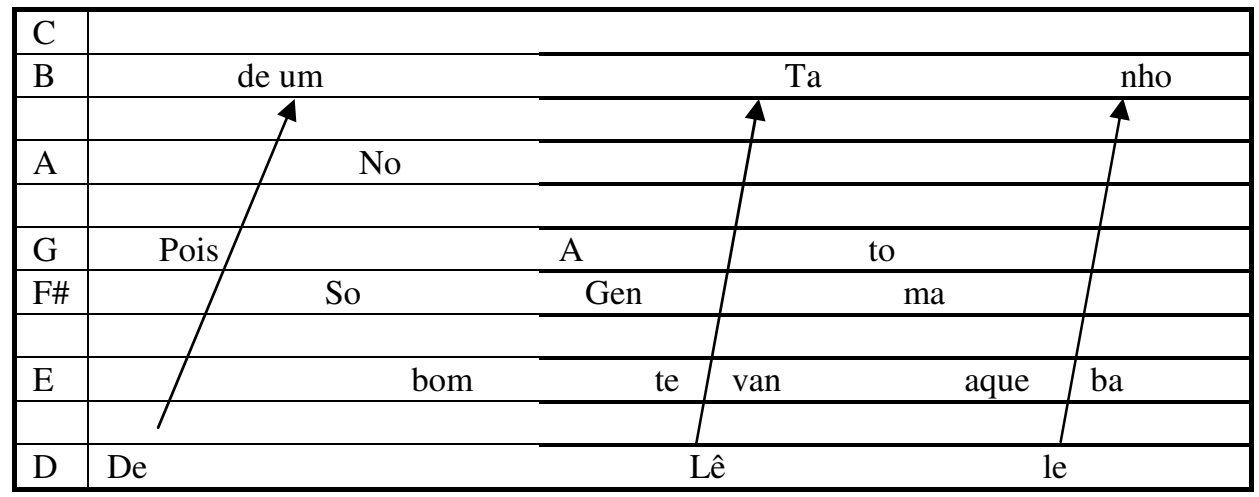

Tabela 2

\begin{tabular}{|c|c|c|c|c|c|c|}
\hline $\mathrm{C}$ & to & $\mathrm{ca}$ & & & & \\
\hline $\mathrm{B}$ & 1 & & & To & & ra \\
\hline & & & & 4 & & 4 \\
\hline \multicolumn{7}{|c|}{ hora } \\
\hline & & & & & & \\
\hline $\mathrm{G}$ & mar & & é o & & que a & \\
\hline \multirow[t]{2}{*}{ F\# } & & fé & & & & \\
\hline & & & $\mathrm{Ca}$ & & $\mathrm{ma}$ & \\
\hline $\mathrm{E}$ & $\mathrm{Na}$ & & fé & lê & mãe & pa \\
\hline & & & & & & \\
\hline $\mathrm{D}$ & & & & & pre & \\
\hline
\end{tabular}

Tabela 3

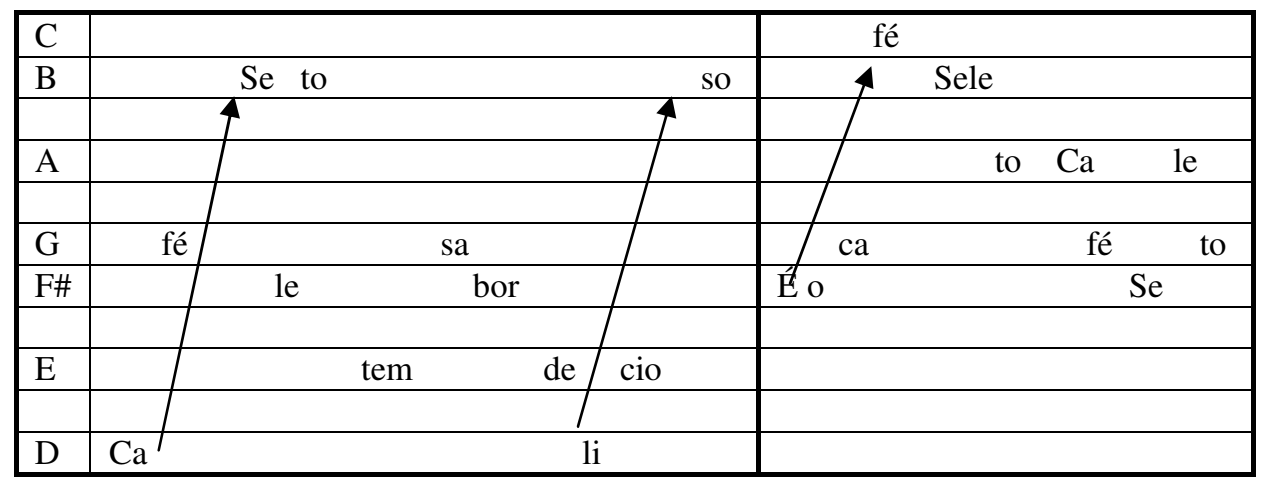


Diagrama 1

Alimento

Alimento

"Essencial"

"Não-Consumível"
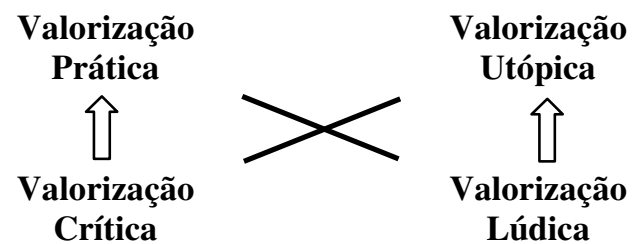

Alimento

"Fundamental"

Alimento

"Supérfluo"

Como citar este artigo:

SHIMODA, Lucas Takeo. Café com leite: simulacros da criança em jingle infantis. Estudos Semióticos. [online] Disponível na Internet via WWW.URL: http://www.fflch.usp.br/dl/semiotica/es. Editor Peter Dietrich. Número 4, São Paulo, 2008.

Acesso em "dia/mês/ano". 